\title{
Nuclear-encoded Mitochondrial Precursor Protein: Intramitochondrial Delivery to Dendrites and Axon Terminals of Neurons and Regulation by Neuronal Activity
}

\author{
Suyan Liu and Margaret Wong-Riley \\ Department of Cellular Biology and Anatomy, Medical College of Wisconsin, Milwaukee, Wisconsin 53226
}

Mitochondria contain hundreds of proteins, most of which are encoded by the nucleus. In neurons, distal dendrites and axon terminals can be separated from the nucleus by a great distance, and the mechanism by which precursor proteins reach distal neuronal processes is not well understood. While our previous study on cytochrome oxidase suggests a posttranslational mechanism of delivery, it is not known whether precursor proteins reach their target processes before or afterincorporation into mitochondria. In order to localize only precursor proteins and not the mature form of the subunit in neurons, we generated polyclonal antibodies against synthetic presequence polypeptides specific to nuclear-encoded subunit IV precursor protein of rat brain cytochrome oxidase. We found that the precursors were located not only in neuronal cell bodies, but also in dendrites and axon terminals. This indicates that the conversion of these precursors to their mature form is not confined to the cell body but occurs in dendrites and axons as well. At the electron microscopic level, an overwhelming majority of immunoreaction product was found within mitochondria, suggesting that precursor proteins are transported to neuronal processes mainly within mitochondria, and that their half-lives are much longer in neurons than in yeast and rat hepatocytes. The precursor pool was downregulated in the rat superior colliculus after monocular enucleation, indicating that precursor synthesis and/or degradation is regulated by neuronal functional activity. These results also suggest that local functional demands may play an important role in controlling the processing of precursors and the assembly of holoenzymes in dendrites and axon terminals. This allows neurons to regulate enzyme levels locally, precisely, and rapidly.

[Key words: antibody production, cytochrome oxidase, immunohistochemistry, immunoelectron microscopy, mitochondrial precursor protein, presequence, regulation]

Mitochondria are ubiquitous organelles found in all cytoplasmic compartments of neurons, and their numerous proteins constitute about $10-20 \%$ of intracellular proteins. However, the $\mathrm{mi}$ -

\footnotetext{
Received Aug. 31, 1993; revised Feb. 16, 1994; accepted Mar. 2, 1994.

We thank Drs. A. L. Haas, E. L. Krug, D. A. Riley, R. Sabina, and R. F. Hevner for helpful discussions and advice, and Z. Huang and F. Nie for assistance in the laboratory. This work was supported by Grants NS18122 and EY05439 from the National Institutes of Health.

Correspondence should be addressed to Dr. Margaret Wong-Riley, Department of Cellular Biology and Anatomy, Medical College of Wisconsin, 8701 Watertown Plank Road, Milwaukee, WI 53226.

Copyright (C) 1994 Society for Neuroscience $0270-6474 / 94 / 145338-14 \$ 05.00 / 0$
}

tochondrial genome encodes only a small fraction of proteins necessary for electron transport and oxidative phosphorylation, and the vast majority of proteins are specified by nuclear genes and are imported into mitochondria (Maccecchini et al., 1979; Kaput et al., 1982; Viebrock et al., 1982). In neurons, dendritic and axonal mitochondrial genomes can be separated from the nucleus by a great distance. To maintain functions in distal processes, neurons must have efficient ways to deliver nuclearderived precursor proteins to mitochondria in these regions. The mechanism underlying transportation and distribution of these proteins to dendrites and axon terminals is poorly understood.

Nuclear-encoded mitochondrial proteins could be transported to dendrites by one of two mechanisms: (1) pretranslational mechanism: mRNAs are delivered to dendrites where they are translated into proteins; and (2) posttranslational mechanism: proteins are translated in the cell body and subsequently transported to dendrites. In the case of cytochrome oxidase (CO), nuclear-derived mRNAs for subunits IV and VIII are detected exclusively in neuronal cell bodies and proximal dendrites (Hevner and Wong-Riley, 1991). This signifies that the delivery of newly synthesized proteins to distal dendrites is via a posttranslational mechanism. Delivery to axon terminals is expected to be posttranslational, as axons lack mRNA and ribosomes. $\mathrm{Nu}-$ clear-encoded mitochondrial proteins are synthesized on cytoplasmic polysomes as large precursor proteins with cleavable $\mathrm{N}$-terminal presequences, which function as mitochondrial targeting signals (Maccecchini et al., 1979; Kaput et al., 1982; Viebrock et al., 1982). Are the precursor proteins transported to dendrites and axons before or after incorporation into the mitochondrial compartment? If the transportation is mediated by mitochondria, can the precursor proteins be detected in neurons in vivo, since their reported half-lives are only seconds to minutes in yeast and in rat hepatocytes (Mori et al., 1981; Reid et al., 1982)?

To clarify these issues, we used $\mathrm{CO}$ subunit IV specified by nuclear genes as a model system to study the distribution of precursor proteins in the rat brain. In order to label precursor proteins and not the mature form, we generated polyclonal antibodies against synthetic presequence specific only to the precursor form of rat brain CO subunit IV (pCOIV; Goto et al., 1989). Although all presequences of nuclear-encoded mitochondrial proteins share the same characteristics (such as a richness in basic and hydroxylated amino acids), there is no sequence consensus among them (Hartl et al., 1989). The specificity of antibodies to pCOIV was tested by ELISA and Western blots. Anti-pCOIV antibodies were applied to rat brain sections for 
immunohistochemical localizations of pCOIV at light and electron microscopic (EM) levels. The pattern of pCOIV distribution was also compared with that of the mature form of $\mathrm{CO}$ subunit IV (Hevner and Wong-Riley, 1989) and with that of CO activity demonstrated histochemically (Wong-Riley, 1979). Several brain regions with clear segregation of dendritic and somatic zones, such as cerebellum, hippocampus, olfactory bulb, and posteromedial barrel subfield, were examined.

Previously, we have shown that the local activity of $\mathrm{CO}$, imposed by neuronal functional activity, is determined by local distribution of enzyme molecules and is regulated at protein and subunit mRNA levels in the monkey brain (Hevner and Wong-Riley, 1989, 1990, 1991). This implies that the rate of $\mathrm{CO}$ subunit synthesis and/or degradation can be regulated by local energy demands. Are intramitochondrial precursor pools in the brain also regulated by neuronal functional activity? To address this question, monocular enucleation was performed on rats to prevent retinal impulses from reaching visual centers in the brain. Possible changes in the level of pCOIV were examined in a major retinal-recipient center, the superior colliculus.

\section{Materials and Methods}

Peptides synthesis and antibody production

The peptide used in this study was based on the sequence Met-LeuAla-Thr-Arg-Ala-Leu-Ser-Leu-Ile-Gly-Lys-Arg-Ala-Ile-Ser-Thr-Ser-ValCys, corresponding to the first 20 residues (out of a total of 22) at the amino terminus of the rat brain CO subunit IV precursor protein (Goto et al., 1989). Polypeptides were synthesized on a MilliGen 9050 peptide synthesizer using the solid-phase method, and reached an approximate $100 \%$ purity without high-performance liquid chromatography (HPLC) purification.

The synthetic peptides were coupled to the carrier protein keyhole limpet hemocyanin (KLH) via a glutaraldehyde linkage. Equal amounts (on a weight basis) of peptide and KLH were dissolved in absolute dimethyl sulfoxide (DMSO) and in $0.1 \mathrm{~m}$ triethylamine chloride, $\mathrm{pH} 9$, respectively, and were then mixed. Cross-linking was carried out by the addition of glutaraldehyde ( $1^{\circ}$ grade) to a final concentration of $25 \mathrm{~mm}$, and the mixture was incubated at room temperature (RT) for $1 \mathrm{hr}$. Sodium cyanoborohydride was added to the above mixture (final concentration, $0.1 \mathrm{~m}$ ) overnight at RT, with gentle agitation. Excess free peptides and glutaraldehyde were removed by dialysis (dialysis membrane MW cutoff, 3500) in $0.1 \mathrm{M}$ phosphate-buffered saline (PBS), $\mathrm{pH}$ 7.4 , with several changes overnight at $4^{\circ} \mathrm{C}$. Synthetic peptides coupled to bovine serum albumin (BSA) in an identical manner were used as controls.

Female New Zealand White rabbits received initial injections of 1 $\mathrm{mg}$ of peptide-glutaraldehyde-KLH conjugates, containing $0.5 \mathrm{mg}$ of peptides emulsified with complete Freund's adjuvant, at 30-40 intradermal sites on the animal's back. After 10 and 13 weeks, boosts were given with injections of $1 \mathrm{mg}$ of conjugates emulsified with Freund's adjuvant ( 1 of 10 complete, 9 of 10 incomplete) at 8-10 multiple intradermal sites.

\section{$\operatorname{IgG}$ affinity purification}

Affinity columns were made by coupling synthetic presequence peptides to Affi-gel 10 (Bio-Rad) through activated ester ( $N$-hydroxysuccinimide) bonds. One milligram of peptide was dissolved in $5 \mathrm{ml}$ of absolute DMSO and $5 \mathrm{ml}$ of $40 \mathrm{~mm}$ HEPES was added to the peptide solution, adjusted to $\mathrm{pH} 9.4$ with $1 \mathrm{~N} \mathrm{Na}$ hydroxide. The peptide solution was mixed with $5 \mathrm{ml}$ gel bed of Affi-gel 10 and reacted at RT for $1 \mathrm{hr}$ with constant agitation. One milliliter of $1 \mathrm{M}$ ethanolamine, $\mathrm{pH} 8.5$ (about $0.1 \mathrm{ml} / \mathrm{ml}$ of gel bed) was added to the mixture and incubated at RT for $1 \mathrm{hr}$. The gel slurry was then transferred to a column and subsequently equilibrated with $30 \mathrm{ml}$ of $40 \mathrm{~mm}$ HEPES, $\mathrm{pH} 7.4 ; 30 \mathrm{ml}$ of $1 \% \mathrm{BSA}$ in HEPES, pH 7.4; $15 \mathrm{ml}$ of $0.1 \mathrm{~m}$ glycine, $\mathrm{pH} 2.6$; and $30 \mathrm{ml}$ of HEPES. IgGs against the presequence of subunit IV precursor were purified by passing antisera over the affinity column followed by washing with 10 gel bed volumes of $40 \mathrm{~mm}$ HEPES and 10 gel bed volumes of HEPES containing $0.5 \mathrm{M} \mathrm{NaCl}$ and $0.5 \%$ Triton $\mathrm{X}-100$. The column was then eluted with $15 \mathrm{ml}$ of $0.1 \mathrm{M}$ glycine, $\mathrm{pH} 2.6$. Purified IgGs were neutralized with $1 \mathrm{~m}$ Tris buffer, $\mathrm{pH} 10$, immediately. The concentration of purified IgG solution was determined spectrophotometrically at 280 $\mathrm{nm}$, using an extinction cocfficient of 1.4 (Harlow and Lane, 1988) Since some affinity-purified IgGs were denatured during IgG purification, the concentration of purified functional IgGs was estimated from ELISA assays.

\section{Preadsorption of anti-pCOIV}

Purified IgGs to the presequence of pCOIV were solid-phase adsorbed by passing through an affinity column made up of presequence peptides coupled to Affi-gel 10, as described above. Preadsorbed anti-pCOIV IgGs were used as controls for immunoblot, immunohistochemistry, and immuno-EM.

\section{Enzyme-linked immunosorbent assays}

Polyclonal antibodies to the presequence of pCOIV were screened with the synthetic presequence peptides using enzyme-linked immunosorbent assays (ELISAs). The antibody titer, defined as the highest antibody dilution at which immunoreaction product can be detected, was also determined by FI ISA. Because of the hydrophobic properties of synthetic peptides, they were dissolved in a solution of absolute DMSO at a concentration of $1 \mu \mathrm{g} / 50 \mu \mathrm{l}$. This was added to each well of polystyrene microtiter plates (Dynatech Immulon II) followed by the addition of 50 $\mu$ l of $0.1 \mathrm{M} \mathrm{NaHCO}, \mathrm{pH} \mathrm{9.0.} \mathrm{Two} \mathrm{micrograms} \mathrm{of} \mathrm{peptide-carrier} \mathrm{protein}$ conjugates (containing $1 \mu \mathrm{g}$ of peptides and $1 \mu \mathrm{g}$ of $\mathrm{KLH}$ or BSA) in $100 \mu 1$ of $0.1 \mathrm{M} \mathrm{NaHCO}_{3}, \mathrm{pH} \mathrm{9,} \mathrm{were} \mathrm{added} \mathrm{to} \mathrm{each} \mathrm{well.} \mathrm{Plates} \mathrm{were}$ incubated overnight at $4^{\circ} \mathrm{C}$ and then blocked with $5 \%$ nonfat dry milk (NFDM) in $0.1 \mathrm{M}$ PBS for $1 \mathrm{hr}$ at RT. Antisera and secondary antibodies (goat anti-rabbit IgG-HRP, 1:1000) were diluted with 5\% NFDM in PBS and reacted at RT for 1-2 hr. All antisera dilutions were tested in duplicates. Color was developed with $2,2^{\prime}$-azinobis (3-ethylbenzothiazoline-6-sulfonic acid). The absorbance of each well at $650 \mathrm{~nm}$ was recorded using a Bio-Rad ELA reader.

Seven controls were used for affinity-purified IgG screening: (1) KLH, (2) BSA, (3) cytochrome $P_{450}$ synthetic peptides, (4) BSA linked to $P_{450}$ peptides via glutaraldehyde, (5) bovine heart $C O$ holoenzyme, (6) affinity-purified IgG preadsorbed with synthetic prescquence peptides, and (7) no primary antibody.

ELISA assays were also used for the possible detection of free presequence peptides of pCOIV from crude rat brain tissue. Samples were homogenized and solubilized in isolation buffer (10 mM Tris, $10 \%$ sucrose, and $5 \%$ Triton $X-100$ ) containing protease inhibitors $[0.1 \mathrm{mM}$ $N$-tosyl-L-lysine chloromethyl ketone, $0.1 \mathrm{~mm}$ L-1-chlor-3-(4-tosylamido)-4-phenyl-2-butanon, $1 \mathrm{~mm}$ phenylmethanesulfonyl fluoride, $5 \mathrm{mM}$ $\mathrm{N}$-ethylamaleimide, $2 \mu \mathrm{g} / \mathrm{ml}$ leupeptin, $5 \mathrm{~mm}$ EDTA] for $8 \mathrm{hr}$ at RT. The homogenate was centrifuged at $45,000 \mathrm{rpm}$ for $30 \mathrm{~min}$, and proteins were separated based on molecular weights with an ultrafree-MC filter unit (exclusion MW, $5000 \mathrm{Da}$; Millipore) at $2000 \times \mathrm{g}$ for $30 \mathrm{~min}$ to separate free peptides (MW $<2200 \mathrm{Da}$ ) of pCOIV from their precursor proteins ( $\mathrm{MW}>19,000 \mathrm{Da})$. Two protein fractions $(\mathrm{MW}>$ or $<5000$ $\mathrm{Da}$ ) were obtained, and 20-100 $\mu \mathrm{g}$ of protcins or peptides was applied to microtiter plates. Since the brain homogenate contained 5\% Triton $\mathrm{X}-100$, and small peptides often do not have affinity for polystyrene, we used ELISA microtiter plates (Pierce Chemical Co.) that contained maleic anhydride, which could spontaneously couple to primary amines of peptides or proteins. The remaining steps were the same as for the above ELISA assays. A control was designed to test whether free presequence peptides in brain homogenates could be degraded during protein solubilization. Synthetic presequence peptides were added to brain homogenates to yield a concentration of $2 \mu \mathrm{g} / 100 \mu \mathrm{l}$ homogenate. ELISA assays were done at 0,4 , and $8 \mathrm{hr}$ after peptide addition, and levels of immunoreaction product from these incubation times were assessed.

\section{Gel electrophoresis}

Cortical gray matter and caudate nucleus of adult Sprague-Dawley rats were homogenized with a Potter-Elvehjem type homogenizer in $10 \%$ sodium dodecyl sulfate (SDS), containing protease inhibitors to yield a $20 \%$ homogenate ( $4 \mu \mathrm{l}$ of $10 \%$ SDS to $1 \mathrm{mg}$ of brain tissue). The $20 \%$ homogenate was solubilized at RT overnight and centrifuged at 45,000 rpm for $30 \mathrm{~min}$. The supernatant was saved and processed for gel clcctrophoresis.

Homogenized tissue samples were run on SDS-15\% polyacrylamide slab gels; $2 \times$ sample buffer contained 0.125 M Tris, $40 \%$ glycerol, 200 $\mathrm{mm}$ dithiothreitol, and $0.01 \%$ bromophenol blue, $\mathrm{pH} 6.8$. Crude rat 
brain homogenates were also run on an $18 \%$ SDS-PAGE to rule out the possibility of labeling frec prescquence peptides, and synthetic presequence peptides were used as a molecular weight standard. The gels were processed for immunoblotting or for Coomassie blue (R-250) staining as described in our previous study (Hevner and Wong-Riley, 1989).

\section{Immunoblotting}

The gels were washed with three changes of cold transfer buffer $(25 \mathrm{~mm}$ Tris, $192 \mathrm{~mm}$ glycine, and $20 \%$ methanol, pH 8.3) for $25 \mathrm{~min}$. Separated proteins were transferred to nitrocellulose based on the procedure of Kuhn-Nentwig and Kadenbach (1985). Nitrocellulose was dried in a $65^{\circ} \mathrm{C}$ oven for $30 \mathrm{~min}$ and blocked with 5\% NFDM and $1 \%$ BSA in 150 mM Tris, $0.89 \%$ saline buffer, and $0.2 \%$ Tween 20 (TBST) overnight at $4^{\circ} \mathrm{C}$. Subsequently, blots were incubated with primary antibodies (affinity-purified IgG against pCOIV) diluted in the blocking solution at a final concentration of $1: 1000-2000$ for $6 \mathrm{hr}$ at RT. The same concentration of anti-pCOIV IgG preadsorbed with synthetic presequence peptides was used as a control. Blots were washed with three changes of TBST and reacted with secondary antibodies (Bio-Rad blotting grade goat anti-rabbit IgG-HRP) at a concentration of $1: 10,000$ for $1 \mathrm{hr}$ at RT. Immunoreaction bands werc visualized by an cnhanced chemiluminescence Western blot reagent (a light-emitting nonradioactive reagent) according to the manufacturer's instructions (Amersham Life Science). The amounts of precursor and mature forms of $\mathrm{CO}$ subunit IV were measured by Molecular Dynamic laser densitometer.

\section{Protein assay}

All protein amounts were determined by means of bicinchoninic acid protein assay, based on the method of Fujimoto et al. (1985). Assay reagents were purchased from Pierce Chemical Co.

\section{Animal tissue preparation}

Adult female Sprague-Dawley rats were used in this study. Animals were anesthetized with an intraperitoneal injection of sodium pentobarbital $(40 \mathrm{mg} / \mathrm{kg}$ body weight) and were perfused via the left ventricle with $80 \mathrm{ml}$ of $0.1 \mathrm{M}$ PBS $\left(37^{\circ} \mathrm{C}\right)$ followed by $200 \mathrm{ml}$ of the fixative $(4 \%$ paraformaldehyde in $4 \%$ sucrose, $0.1 \mathrm{M}$ PBS, $\mathrm{pH} 7.4$ ) at $4^{\circ} \mathrm{C}$. For EM study, the fixative used was $2.5 \%$ paraformaldehyde and $1.5 \%$ glutaraldehyde in $0.1 \mathrm{M}$ PBS, $\mathrm{pH} 7.4$, and $4 \%$ sucrose. Brains were removed and post fixed in the same fixative for $1 \mathrm{hr}$ followed by extensive washing in $0.1 \mathrm{M}$ PBS with $4 \%$ sucrose. For light microscopic immunohistochemical study, brain tissues were cryoprotected in $10 \%, 20 \%$, and $30 \%$ sucrose in $0.1 \mathrm{M}$ PBS and frozen-sectioned coronally at $15 \mu \mathrm{m}$ thickness. Alternate sections were processed for (1) $\mathrm{CO}$ histochemistry, (2) immunohistochemistry of pCOIV antibodies, and (3) immunohistochemistry of polyclonal antibodies raised against $\mathrm{CO}$ holoenzyme, recognizing primarily CO subunit IV (Hevner and Wong-Riley, 1989). We will refer to the latter antibodies as anti-COIV in the present study. For EM, the cerebellum was placed in the original buffer overnight at $4^{\circ} \mathrm{C}$ and vibratome sectioned in the coronal plane at $50 \mu \mathrm{m}$ thickness. Adult LongEvans rats with pigmented eyes were used to study the regulation of pCOIV in the visual system. Left eyes of these animals were removed by surgical excision under anesthesia and the animals survived for 3 or $15 \mathrm{~d}$.

\section{CO histochemistry}

$\mathrm{CO}$ histochemistry was performed according to our protocol (WongRiley, 1979). Briefly, 15-20 $\mu \mathrm{m}$ frozen sections were incubated in reaction medium containing $0.05 \%$ diaminobenzidine (DAB) and $0.02 \%$ cytochrome $\mathrm{c}$ in $0.1 \mathrm{~m}$ PBS and $4 \%$ sucrose for approximately $2-3 \mathrm{hr}$ with gentle agitation at $37^{\circ} \mathrm{C}$.

\section{Light microscopic immunohistochemistry}

All reactions were performed with continuous agitation, and solutions were made in $0.1 \mathrm{M}$ PBS. Sections were blocked with $10 \%$ NFDM, $5 \%$ normal goat serum, and $0.5-1 \%$ Triton X-100 overnight at $4^{\circ} \mathrm{C}$. Alternate sections were incubated with anti-pCOIV $(1: 2000-10,000)$ or antiCOIV (1:5000) in the same blocking solution for $24-48 \mathrm{hr}$ at $4^{\circ} \mathrm{C}$. The sections were rinsed for $1 \mathrm{hr}$ with three changes of PBS and processed for avidin/biotin peroxidase complex reactions (ABC; Elite $A B C$ kit, Vector Laboratories). Sections were incubated in biotinylated goat antirabbit $\mathrm{IgG}$ at 1:200 dilution for $1 \mathrm{hr}$ at $\mathrm{RT}$. After an additional $1 \mathrm{hr}$ rinse with PBS, sections were placed in PBS containing $\mathrm{ABC}(1: 200)$ for $1 \mathrm{hr}$ at RT followed by a thorough rinsing in PBS. Immunoreactivity was finally developed by incubation in a solution of $0.05 \% \mathrm{DAB}$ and $0.01 \%$ hydrogen peroxide for $2-7 \mathrm{~min}$. Anti-pCOIV preadsorbed with affinity-purified IgG against COIV presequence peptides was used as an immunohistochemical control. Since the amount of pCOIV in the brain was expected to be fairly low, an equal amount of normal rabbit IgG was used as an additional control against nonspecific immunostaining of other proteins in the brain.

\section{Optical density analysis}

To assess the intensity of reaction product of $\mathrm{CO}$ histochemistry and immunohistochemistry of COIV and pCOIV, optical density measurements were made on superior colliculus of monocularly enucleated rats by means of a Zeiss photometer attached to a Zeiss compound microscope. Twenty to 30 readings were taken from each layer. All lighting conditions, magnifications, and reference points were kept constant.

\section{Immunoelectron microscopy}

Preembedding. Vibratome sections were blocked with PBS containing $5 \%$ NFDM, $5 \%$ NGS, $0.1-0.5 \%$ Triton X-100 overnight at $4^{\circ} \mathrm{C}$ and incubated with purified $\mathrm{IgG}$ against pCOIV diluted at 1:1000 with the blocking solution for $48 \mathrm{hr}$ at $4^{\circ} \mathrm{C}$. Sections were processed for the $\mathrm{ABC}$ immunohistochemical procedure as described above and embedded in Epon-Araldite (Wong-Riley, 1979).

Postembedding. Vibratome sections $(100 \mu \mathrm{m})$ were osmicated in $1 \%$ osmium tetroxide for $30 \mathrm{~min}$ at RT and were then dehydrated in alcohol series as above. Tissues were embedded in Durcupan resin. Ultrathin sections were mounted on non-Formvar-coated fine nickel mesh grids and were pretreated with $1 \%$ periodic acid for $10 \mathrm{~min}$, followed by $10 \%$ sodium metaperiodate for $15 \mathrm{~min}$, and $1 \%$ sodium borohydride for 3 min. Sections were blocked with $5 \%$ BSA in $0.1 \%$ Triton $X-100,50 \mathrm{~mm}$ Tris, and $0.9 \%$ sodium chloride (TTBS), pH 7.4, for $30 \mathrm{~min}$. They were then incubated with primary antibodies (affinity-purified anti-pCOIV IgG or antisera) at dilutions of 1:100-200 in TTBS containing 5\% BSA for $15-40 \mathrm{hr}$ at RT. The grids were blocked with $1 \% \mathrm{BSA}$ in TTBS for $30 \mathrm{~min}$ and then reacted with $10 \mathrm{~nm}$ gold-labeled GaR IgG (diluted $1: 40$ in TTBS containing $0.1 \%$ BSA, pH 8.2) for $1 \mathrm{hr}$ at RT. They were washed with TTBS between each step and were agitated gently for all reactions and wash steps. Finally, the grids were stained with uranyl acetate and lead citrate and examined with a JEOL (JEM-100 CX II) electron microscope.

\section{Immunogold quantitation}

Electron micrographs of the cerebellum were printed at a final magnification of either $35,000 \times$ or $50,000 \times$. Areal measurements of mitochondria and nonmitochondrial cytoplasm were made by means of a BIOQUANT II morphometric program, using a Houston Hipad DT-11 digitizer (Bioquant, $\mathbf{R}$ and $\mathbf{M}$ Biometrics, Inc.) connected to an Apple Ile microcomputer. Gold particles over Purkinje cell bodies and neuronal processes (dendrites, basket terminals, and mossy fiber terminals) were counted from a total area of $310,653 \mu \mathrm{m}^{2}$, including 22 random samples of three rats. To ensure consistency, we measured every mitochondrial area and counted gold particles in a given area for all of our samples. The density of gold particles per unit area of mitochondria was compared to the density of gold particles per unit area of nonmitochondrial cytoplasm. No primary antibodies and anti-pCOIV IgG preadsorbed with synthetic presequence peptides were used as controls. Gold particles over blank space (resin alone) were also assessed. Parametric statistics (Student's $t$ test) were used to analyze differences between groups, and a $p$ value of 0.05 or less was considered significant.

\section{Results}

\section{Specificity of anti-pCOIV}

The specificity of our antibodies (anti-pCOIV) against the presequence of rat brain $\mathrm{CO}$ subunit IV precursor proteins was confirmed by ELISA, Western blot, and immunohistochemistry. The presequence of rat subunit IV precursor was screened with SwissProt and Daemon at GenBank data base, and the amino acid sequence of the presequence is not significantly homologous to those of other proteins, including its mature form, in the rat brain. 


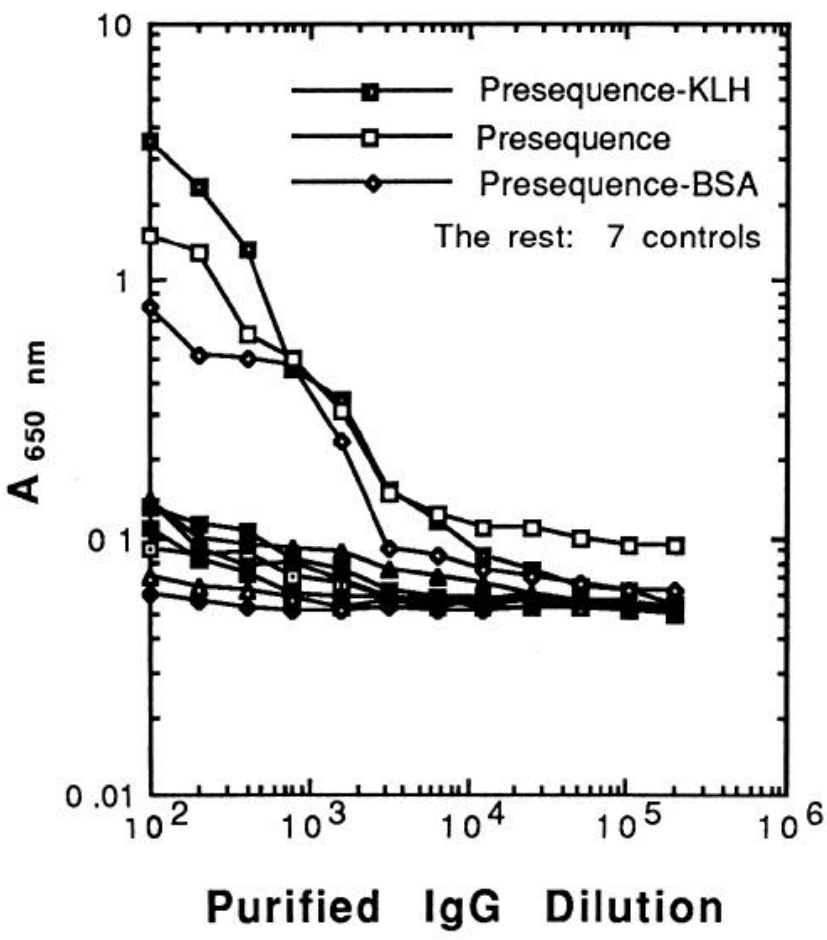

Figure 1. The specificity of anti-pCOIV antibodies was determined by ELISA. Affinity-purified IgGs against the presequence of $\mathrm{CO}$ subunit IV precursor (anti-pCOIV) were screened by synthetic presequence polypeptides and a number of control synthetic polypeptides and proteins. The affinity-purified IgGs reacted only with presequence polypeptides either alone or conjugated to KLH or BSA, but not with any of the following seven controls: synthetic peptide $\mathrm{P}_{450}, \mathrm{KLH}$, BSA, mature bovine heart $\mathrm{CO}$ holoenzyme, BSA linked to $\mathrm{P}_{450}$ peptides via glutaraldehyde, preimmune serum, and no primary antibodies.

ELISA. All antibody titers were determined by ELISA. AntipCOIV antibodies reached the highest titer after the third boost (about 3 months after the first injection), and high titer antibodies were used in all subsequent studies. Antisera had a high titer (diluted at 1:200,000) to the synthetic presequence peptides, while controls (preimmune sera and no primary antibodies) had only background staining (not shown). Besides IgGs against presequence peptides, crude antisera also contained abundant IgGs to the carrier protein $\mathrm{KLH}$ and to the coupling reagent glutaraldehyde. It was therefore necessary to purify IgGs against presequence peptides from crude antisera. Affinity-purified IgGs reacted specifically with presequence peptides of pCOIV either alone or linked to carrier proteins KLH and BSA, and did not cross-react with any of the seven control proteins, peptides, and glutaraldehyde (Fig. 1).

Western blot. In Western blots of crude rat brain tissue, our previously reported polyclonal antibodies against $\mathrm{CO}$ holoenzyme reacted primarily to the mature form of $\mathrm{CO}$ subunit IV and weakly to subunit II (Hevner and Wong-Riley, 1989; antiCOIV). We presume that it also reacted to the mature portion of the precursor form of subunit IV (Fig. 2, lane 1). On the other hand, our present anti-pCOIV reacted only with the precursor form of COIV but not with its mature form (Fig. 2, lane 2). No significant immunoreactive bands were detected in lane 3 (preadsorbed with synthetic presequence peptides) or lane 4 (no primary antibodies). $\mathrm{CO}$ subunits were identified using the nomenclature of Kadenbach et al. (1983). Gel densitometry of lane

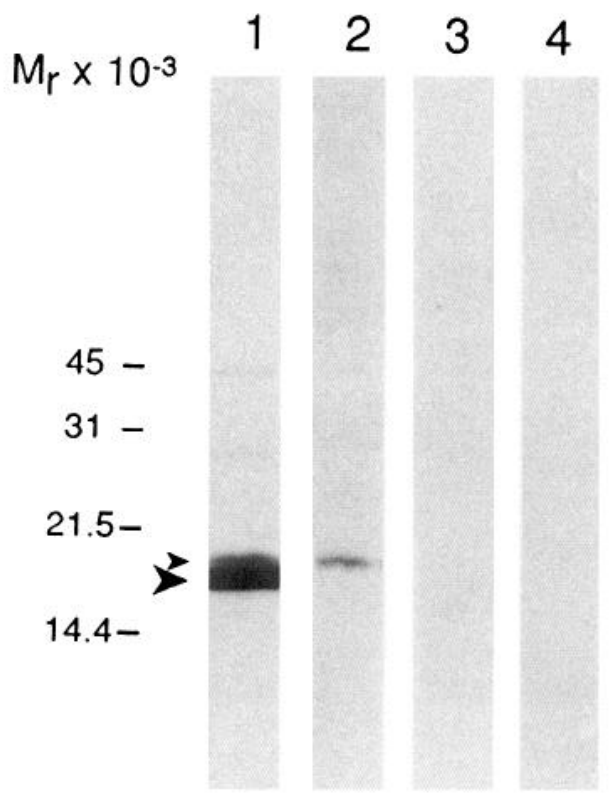

Figure 2. Crude rat brain tissue was homogenized in 10\% SDS containing protease inhibitors, and proteins were separated by SDS- $15 \%$ PAGE (100 $\mu$ g protein/lane). The proteins were subsequently transferred to nitrocellulose and immunoblotted using anti-pCOIV or anti-COIV antibodies. The immunoreactive bands were visualized by ECL Western blot reagents. Lane 1, Anti-COIV reacts with precursors of $\mathrm{CO}$ subunit IV (upper small arrowhead; $M_{r}, 19.1 \mathrm{kDa}$ ) as well as mature CO subunit IV (lower arrowhead; $M_{r}, 17.5 \mathrm{kDa}$ ). In addition, anti-COIV also reacts slightly with $\mathrm{CO}$ subunit II $\left(M_{r}: 27.5 \mathrm{kDa}\right)$ as shown in our previous study (Hevner and Wong-Riley, 1989). Lane 2, Anti-pCOIV reacts with pCOIV but not with the mature form of COIV. Lane 3, Purified IgG preadsorbed with synthetic presequence polypeptides. Lane 4 , No primary antibodies.

1 revealed that the relative amount of pCOIV in brain was 300fold less than that of mature CO subunit IV.

Immunohistochemical specificity was tested in rat cerebellum and hippocampus with anti-pCOIV, IgG preadsorbed with synthetic peptides, and normal rabbit IgG. Strong immunoreactive signals with anti-pCOIV antibodies were seen in both brain regions (Fig. $3 a$; hippocampus not shown). Immunostaining was abolished by preadsorption with affinity purified $\mathrm{IgG}$ against presequence peptides (Fig. $3 b$ ). Additional control sections incubated in normal rabbit IgG also yielded minimal background staining (not shown). This confirms the high specificity of antibodies shown in Figures 1 and 2.

\section{Free presequence peptides in the brain}

In order to exclude the possibility that free presequence peptides may contribute to the bulk of the immunolabeling, Western blots were performed on samples run on $18 \%$ SDS-PAGE. While synthetic presequence peptides clearly yielded definitive crossreactivity (Fig. $4 a$, lane 2), crude rat brain homogenates did not produce any detectable immunoreaction bands in the size range of presequence peptides, but they did give distinct labeling of the precursor protein pCOIV (Fig. $4 a$, lane 1). In addition, ELISA assays showed that immunoreaction product was only detected in the protein fraction with $\mathrm{MW}>5 \mathrm{kDa}$ and not in the fraction with $\mathrm{MW}<5 \mathrm{kDa}$ (Fig. $4 b$ ). This suggests that the level of free presequence peptides in the rat brain tissue is undetectable by the methods used, and that precursor proteins, rather than free presequence peptides, contributed to the bulk of immunohis- 


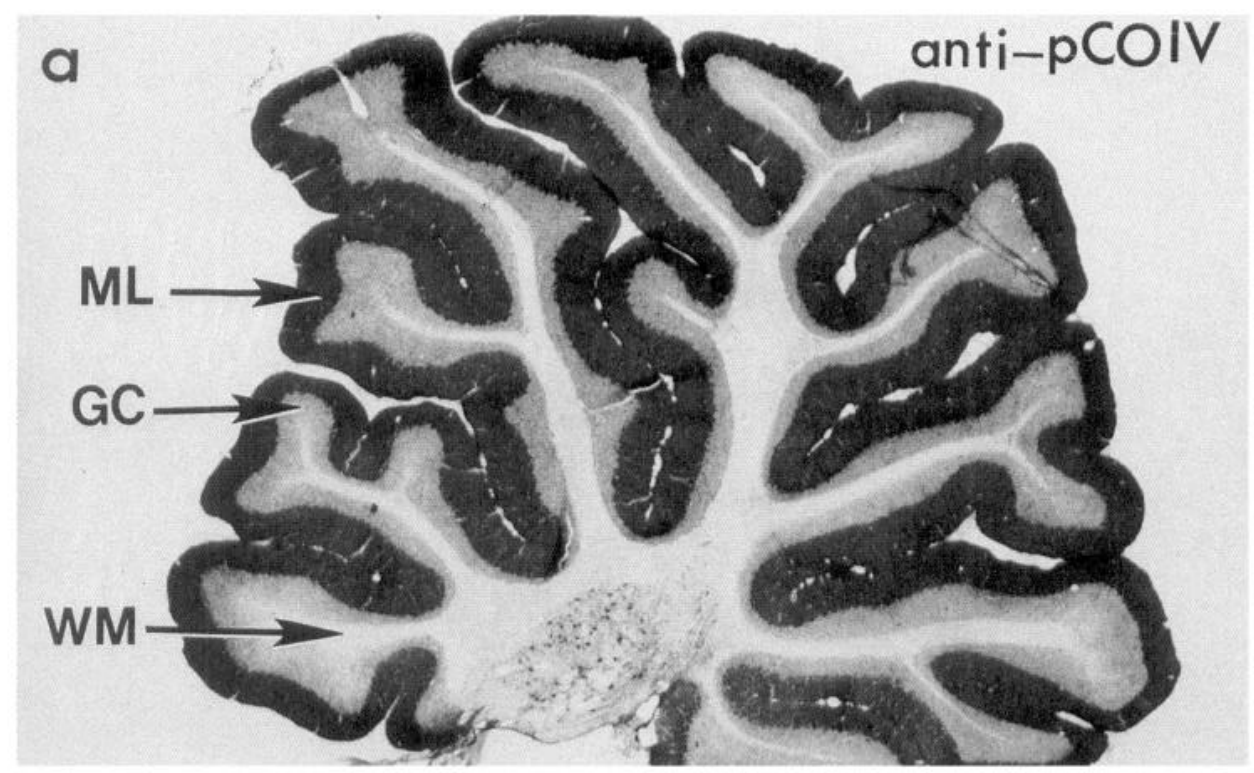

Figure 3. The immunohistochemical specificity of anti-pCOIV was tested in the rat cerebellum. Frozen sections were incubated with anti-pCOIV $(1: 10,000)$ (a) and anti-pCOIV preadsorbed with synthetic presequence polypeptides $(b)$. Primary antibodies were detected using the Elite $\mathrm{ABC}$ kit. In $a$, the level of immunoreactivity is dark in the molecular layer $(M L)$, moderate in the granule cell layer $(G C)$, and light in the white matter $(W M)$. The immunostaining is abolished by preadsorption of anti-pCOIV with synthetic presequence polypeptides $(b)$. Normal IgGs gave nonspecific background staining (not shown). Scale bar, $1 \mathrm{~mm}$.

tochemical staining in the rat brain. To rule out further the possibility that free presequence peptides in brain homogenates might be degraded during protein solubilization (even though protease inhibitors were present), thereby rendering them undetectable, synthetic peptides were added to brain homogenates and ELISA assays were done at 0,4 , and $8 \mathrm{hr}$ time points. Figure $4 c$ demonstrates that there were no significant changes in the intensity of immunoreaction during these incubation times. This indicates that protease inhibitors added to brain homogenates effectively inhibited peptide degradation during protein solubilization.

\section{Cellular localization of $\mathrm{pCOIV}$}

The cellular localization of pCOIV was examined immunohistochemically in several brain regions, including the cerebellum and the dentate gyrus, where neuronal cell bodies were spatially segregated from their dendrites. Purkinje cell bodies were moderately immunoreactive (Fig. $5 a, b$ ). At higher magnifications (Fig. $5 b$ ), we found intense pericellular immunostaining around Purkinje cell bodies, presumably contributed by basket cell ter- minals (see Fig. $6 c$; Mjaatvedt and Wong-Riley, 1988; Hevner and Wong-Riley, 1989). Granule cell bodies showed light immunostaining and adjacent mossy fiber terminals had moderate staining (Figs. 5, 6d). In the cerebellum (Fig. 5) and dentate gyrus, pCOIV labeling was intense within dendritic trees of the respective molecular layers. Dendritic labeling of pCOIV was also observed in other brain regions, such as cerebellar deep nuclei, olfactory bulb, various brainstem nuclei, and posteromedial barrel subfields (data not shown).

\section{Subcellular localization of $\mathrm{pCOIV}$}

Electron microscopic immunocytochemistry of pCOIV was performed by means of pre- and postembedding procedures.

Preembedding. The majority of the immunostaining of pCOIV was found within mitochondria of neuronal cell bodies and dendrites in all cerebellar samples examined (data not shown). No labeling was observed outside of mitochondria in the cytoplasm, or in control experiments using anti-pCOIV IgGs preadsorbed with synthetic presequence peptides. 
a

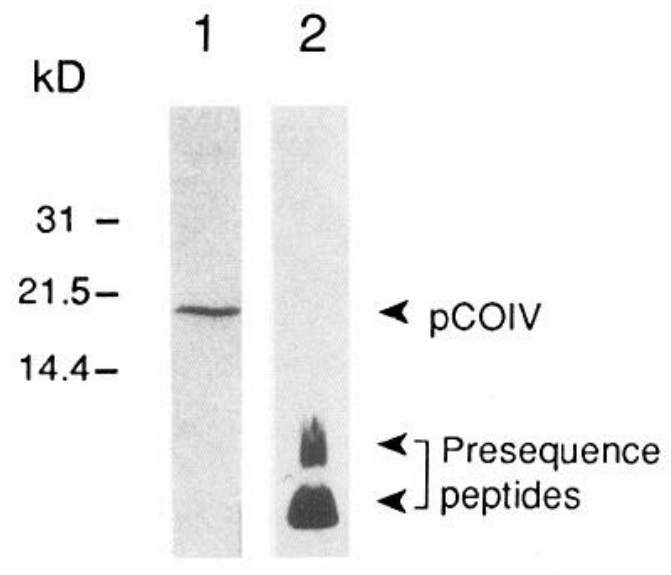

b

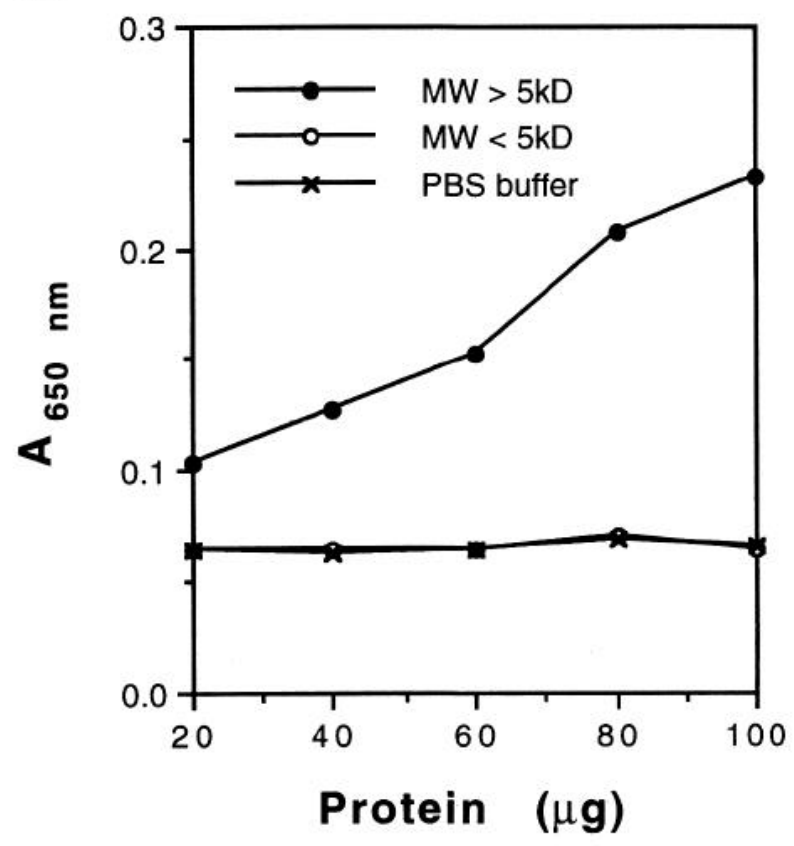

C

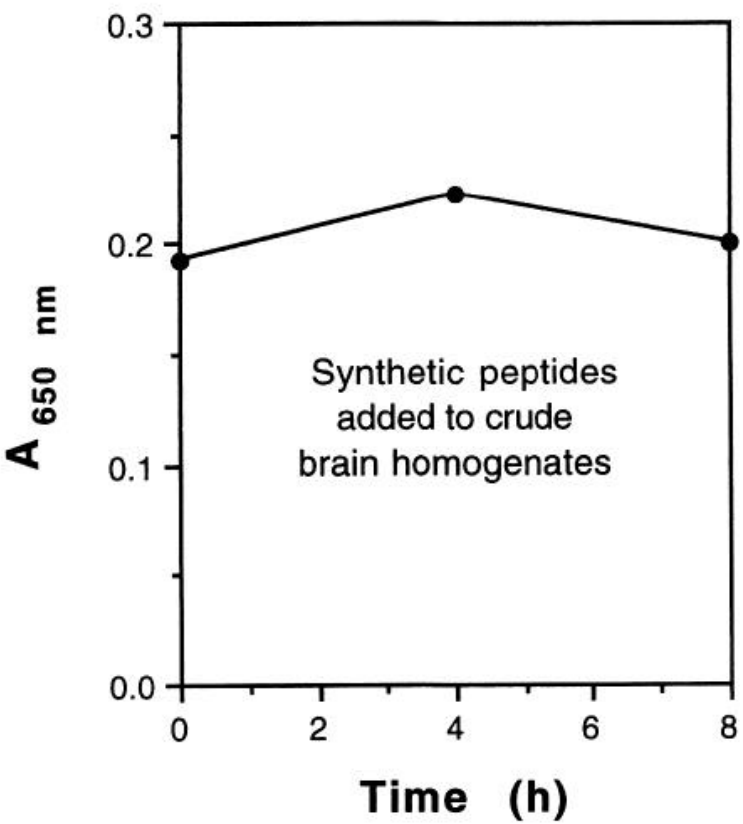

Figure 4. Detecting free presequence peptides in rat brain tissue. $a$, Immunoblot. One hundred micrograms of proteins of crude rat brain homogenates containing protease inhibitors (brain homogenate, lane 1) and $1 \mu \mathrm{g}$ of synthetic presequence peptides (lane 2) were run on 18\% SDSPAGE and probed by anti-pCOIV antibodies. Lane 1 shows a distinct immunoreaction band of precursor protein ( $p C O I V)$, which corresponds to $M, 19 \mathrm{kDa}$. No visible band is present at the MW range below the precursor. Lane 2 demonstrates abundant synthetic presequence peptides detectable with anti-pCOIV. The presence of double bands for synthetic peptides is due to overloading and aggregation of the synthetic peptides. $b$, ELISA assay. Crude rat brain homogenates containing protease inhibitors were solubilized at RT for $8 \mathrm{hr}$, separated into two fractions (MW < $5 \mathrm{kDa}$ or $>5 \mathrm{kDa}$ ), and were then subjected to ELISAs. Immunoreaction product was detectable only in the protein fraction with $\mathrm{MW}>5 \mathrm{kDa}$, while the fraction MW $<5 \mathrm{kDa}$ generated only background color. $c$, Two micrograms of synthetic peptide were added to $100 \mu \mathrm{l}$ of brain homogenates containing protease inhibitors. ELISAs were done at incubation times of 0,4 , and $8 \mathrm{hr}$ after the addition of synthetic peptides. The intensity of immunoreaction products with anti-pCOIV did not decrease with increasing incubation times. 


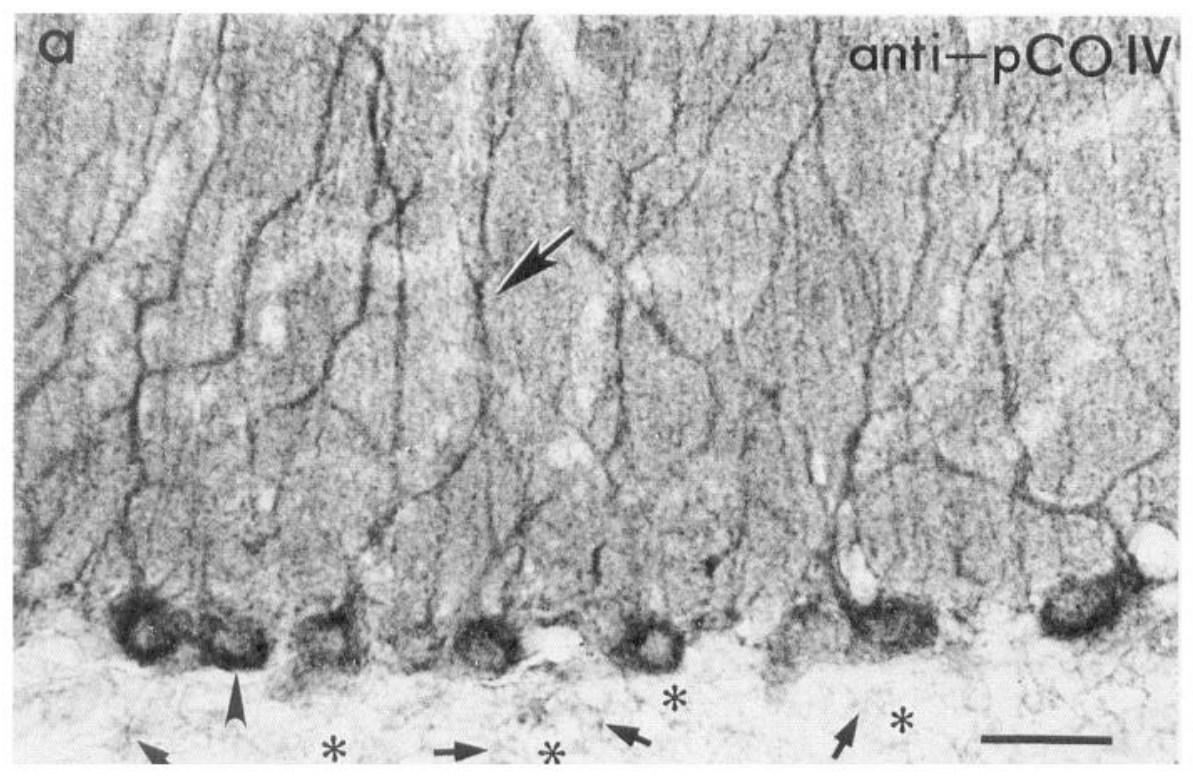

Figure 5. The cellular localization of pCOIV was examined immunohistochemically in frozen rat brain sections. $a$, In the cerebellum, pCOIV immunostaining was found in neuronal cell bodies and dendrites. Large arrow shows Purkinje cell dendrites in the molecular layer with intense pCOIV immunostaining. $b$, At a higher magnification, intense immunostaining over Purkinje cell bodies (arrowheads) was found to mainly be pericellular and presumably contributed by basket cell terminals (also see Fig. 6c). Purkinje cell bodies were moderately stained (open arrow). Granule cell bodies (*) had light immunostaining, while adjacent mossy fiber terminals were moderately immunoreactive (small arrows). Scale bars: $a$, $0.2 \mathrm{~mm} ; b, 0.06 \mathrm{~mm}$.

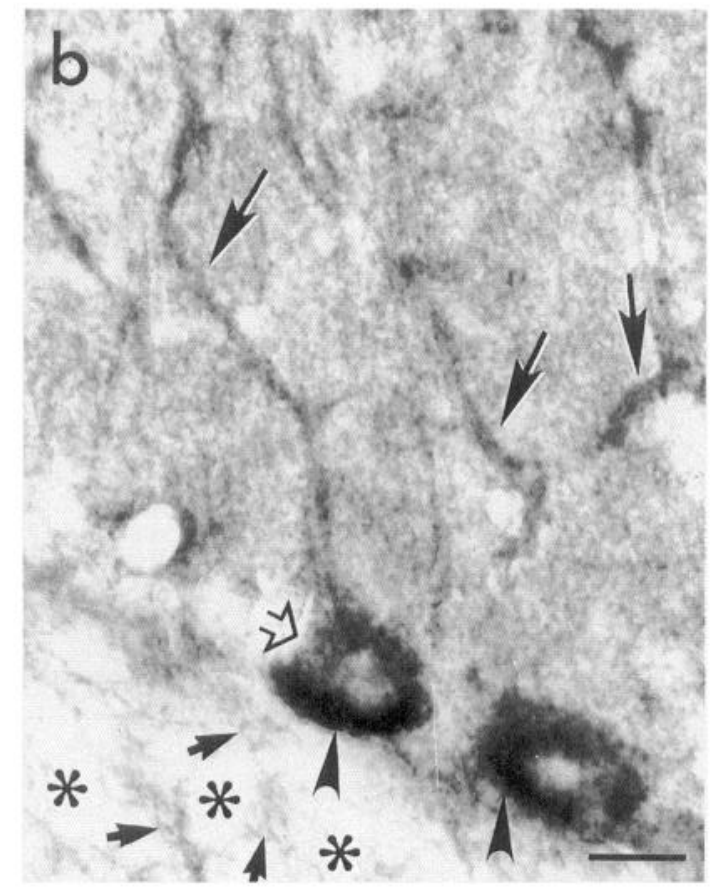

Postembedding. More successful results were achieved with the postembedding method. It offered good ultrastructure and preserved significant amount of specific signals in all three layers of the cerebellum. In the molecular layer, Purkinje cell dendrites were the most immunoreactive elements, and immunogold particles over dendritic mitochondria were found 15 times more frequently than that over the remaining dendritic cytoplasm (Fig. $6 a$, Table 1). Purkinje cell bodies showed only light to moderately immunoreactive mitochondria with few darkly immunoreactive mitochondria (Fig. 6c). Immunogold labeling of mitochondria in Purkinje cell bodies was approximately six times greater than that of nonmitochondrial portion of cytoplasm ( $p$ $<0.0001$; Table 1). This ratio is lower than that of dendrites but significantly higher than those of controls (anti-pCOIV preadsorbed with synthetic peptides and no primary antibodies; the ratio of mitochondria to cytoplasm was $1.3: 1$ ). The slightly higher levels of immunogold particles over somatic cytoplasm than over dendritic cytoplasm may represent newly synthesized pCOIV that had not yet been imported into mitochondria. Basket terminals had intensely immunolabeled mitochondria (Fig. $6 c$ ), and were significantly more immunoreactive than Purkinje cell bodies. This EM observation is consistent with our light microscopic finding. Mossy fiber terminals showed moderately immunoreactive mitochondria (Fig. $6 d$ ). The number of gold particles over their mitochondria was about 11 times higher than that over their nonmitochondrial cytoplasm $(p<0.0001)$. Granule cell bodies had relatively few gold particles over their mitochondria (data not shown). The heterogeneous distribution is in agreement with the pattern shown by $\mathrm{CO}$ histochemistry at the EM level (Mjaatvedt and Wong-Riley, 1988). 


\begin{tabular}{|c|c|c|c|}
\hline Cell compartment & Area $\left(\mu \mathrm{m}^{2}\right)$ & $\begin{array}{l}\text { \# Gold particles/ } \\
\mu \mathrm{m}^{2} \pm \mathrm{SE}\end{array}$ & $\begin{array}{l}\text { Significance of } \\
\text { comparisons }^{a}\end{array}$ \\
\hline \multicolumn{4}{|l|}{ Neuronal processes } \\
\hline a. Mitochondria $(357)^{b}$ & 42.45 & $58.33 \pm 6.26$ & \\
\hline 1. Dendrites (141) & 10.63 & $60.13 \pm 4.80$ & \\
\hline 2. Basket terminals (119) & 14.25 & $68.28 \pm 3.57$ & \\
\hline 3. Mossy fiber terminals (97) & 17.57 & $37.80 \pm 6.40$ & \\
\hline b. Extramito. cytoplasm & 182.1 & $4.76 \pm 0.45$ & \\
\hline a vs b & & & $p<0.0001$ \\
\hline \multicolumn{4}{|l|}{ Cell bodies (Purkinje) } \\
\hline c. Mitochondria (214) & 15.92 & $39.30 \pm 6.55$ & \\
\hline d. Extramito. cytoplasm & 93.71 & $6.55 \pm 0.59$ & \\
\hline c vs d & & & $p<0.0001$ \\
\hline \multicolumn{4}{|l|}{ Control $^{c}$} \\
\hline e. Mitochondria (142) & 10.74 & $6.38 \pm 0.85$ & \\
\hline f. Extramito. cytoplasm & 72.31 & $4.92 \pm 0.81$ & \\
\hline e vs $\mathrm{f}$ & & & NS \\
\hline b vs $f$ & & & NS \\
\hline d vs f & & & NS \\
\hline b vs d & & & $p<0.05$ \\
\hline$a_{1}$ vs c & & & $p<0.05$ \\
\hline$a_{2}$ vs c & & & $p<0.005$ \\
\hline$a_{3}$ vs c & & & NS \\
\hline
\end{tabular}

\section{Correlation of $\mathrm{CO}$ activity with COIV and $\mathrm{pCOIV}$ immunoreactivity}

The distribution of pCOIV was heterogeneous in all rat brain regions examined, and the patterns coincided with those of $\mathrm{CO}$ histochemistry and immunohistochemistry of COIV. In the dentate gyrus of the dendrite-rich molecular layer, the outer portion (distal dendrites) was more immunoreactive than the inner portion (proximal dendrites), and the granule cell layer was only light to moderately reactive. In the olfactory bulb, glomeruli with dendrodendritic synapses were intensely immunoreactive, while the mitral cell body layer and the granule cell layer only showed light to moderate levels of immunostaining. In the posteromedial barrel subfield, the barrel hollows containing dendrites and synapses were darkly stained, whereas the soma-rich barrel sides and the intervening septa had considerably lighter immunostaining (Fig. 7).

\section{The effect of enucleation on the levels of $p C O I V, C O I V$, and CO activity}

The normal rat superior colliculus is composed of three cellular layers interposed by fibrous layers. The relative activity of $\mathrm{CO}$ holoenzyme (demonstrable histochemically) and the relative amounts of COIV and pCOIV (shown immunohistochemically) had comparable patterns of distribution within the superior colliculus (compare left sides of Fig. $8 a-c$ ). The superficial gray layer showed the highest level of staining, the intermediate gray layer was moderately reactive, and the deep gray layer was the least reactive. As early as 3 d after monocular enucleation, levels of CO activity and immunoreactivity of COIV and pCOIV were slightly decreased in neuronal cell bodies and processes within the contralateral superficial gray layer, the major recipient site of retinal input. However, intermediate and deep gray layers were not different from the nondenervated side (data not shown).

Table 2. Effect of $15 \mathrm{~d}$ of left monocular enucleation on relative optical densities of the contralateral superior colliculus of adult rats

\begin{tabular}{|c|c|c|c|c|c|c|c|c|c|}
\hline \multirow{2}{*}{$\begin{array}{l}\text { Methods of } \\
\text { tissue processing }\end{array}$} & \multicolumn{2}{|c|}{$\begin{array}{l}\text { Superficial gray } \\
\text { layer } \\
\text { Mean }^{a} \pm \mathrm{SE} \\
\end{array}$} & \multirow{2}{*}{$\begin{array}{l}\text { Signifi- } \\
\text { cance } \\
\text { (L vs R) }\end{array}$} & \multicolumn{2}{|l|}{$\begin{array}{l}\text { Intermediate } \\
\text { gray layer } \\
\text { Mean }^{a} \pm \mathrm{SE} \\
\end{array}$} & \multirow{2}{*}{$\begin{array}{l}\text { Signifi- } \\
\text { cance } \\
\text { (L vs R) }\end{array}$} & \multicolumn{2}{|l|}{$\begin{array}{l}\text { Deep } \\
\text { gray layer } \\
\text { Mean }^{a} \pm S E\end{array}$} & \multirow{2}{*}{$\begin{array}{l}\text { Signifi- } \\
\text { cance } \\
\text { (L vs R) }\end{array}$} \\
\hline & $\overline{\mathrm{L}}$ & $\mathbf{R}$ & & $\bar{L}$ & $\mathbf{R}$ & & $\overline{\mathrm{L}}$ & $\mathbf{R}$ & \\
\hline CO hist & $1.00 \pm 0.05$ & 0.77 & $p<0.001$ & $1.00 \pm 0.07$ & .06 & 0.001 & $1.00 \pm 0.08$ & 0.9 & 0.05 \\
\hline COIV immunohistochen & $1.00 \pm 0.07$ & $0.74 \pm 0.07$ & $p<0.001$ & $1.00 \pm 0.05$ & $0.88 \pm 0.04$ & $p<0.001$ & $1.00 \pm 0.05$ & $0.95 \pm 0.06$ & $p<0.05$ \\
\hline pCOIV immunohistochemistry & $1.00 \pm 0.05$ & $0.76 \pm 0.02$ & $p<0.001$ & $1.00 \pm 0.02$ & $0.86 \pm 0.03$ & $p<0.001$ & $1.00 \pm 0.03$ & $0.92 \pm 0.02$ & $p<0.01$ \\
\hline
\end{tabular}

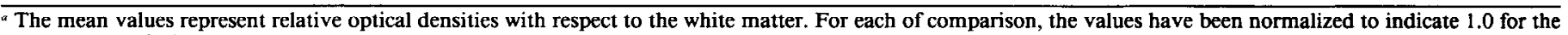
nondeprived left side (L) and corresponding reduced levels for the deprived right side (R). 
Figure 6. Localization of pCOIV in dendrites, cell bodies, and axonal terminals by immunoelectron microscopy. $a$, In the molecular layer of the cerebellum, the majority of immunogold particles were found in mitochondria (arrowheads) of Purkinje cell dendrites $(D)$ and very few gold particles were seen in dendritic cytoplasm outside of mitochondria. $b$, Blank regions of Durcupan resin showed very low counts of immunogold particles (density, 1.9/ $\left.\mu \mathrm{m}^{2}\right) . c$, Purkinje cell body $(P)$ had a heterogeneous distribution of gold-labeled mitochondria (arrowheads). In general, they were light to moderately immunoreactive. Open arrows indicate immunogold particles in nonmitochondrial cytoplasm. A basket terminal $(B)$ adjacent to the Purkinje cell had mitochondria intensely labeled with immunogold. As expected, immunogold particles in nonmitochondrial cytoplasm were slightly more prevalent in cell bodies than in neuronal processes, suggesting that some of the newly synthesized precursor proteins (pCOIV) have not yet been imported into somatic mitochondria. $d$, A mossy fiber terminal contained moderately immunoreactive mitochondria, and immunogold particles were present almost exclusively in mitochondria. Circles show higher concentrations of immunogold particles, and arrowheads indicate isolated gold particles in mitochondria. Scale bars, $1 \mu \mathrm{m}$.

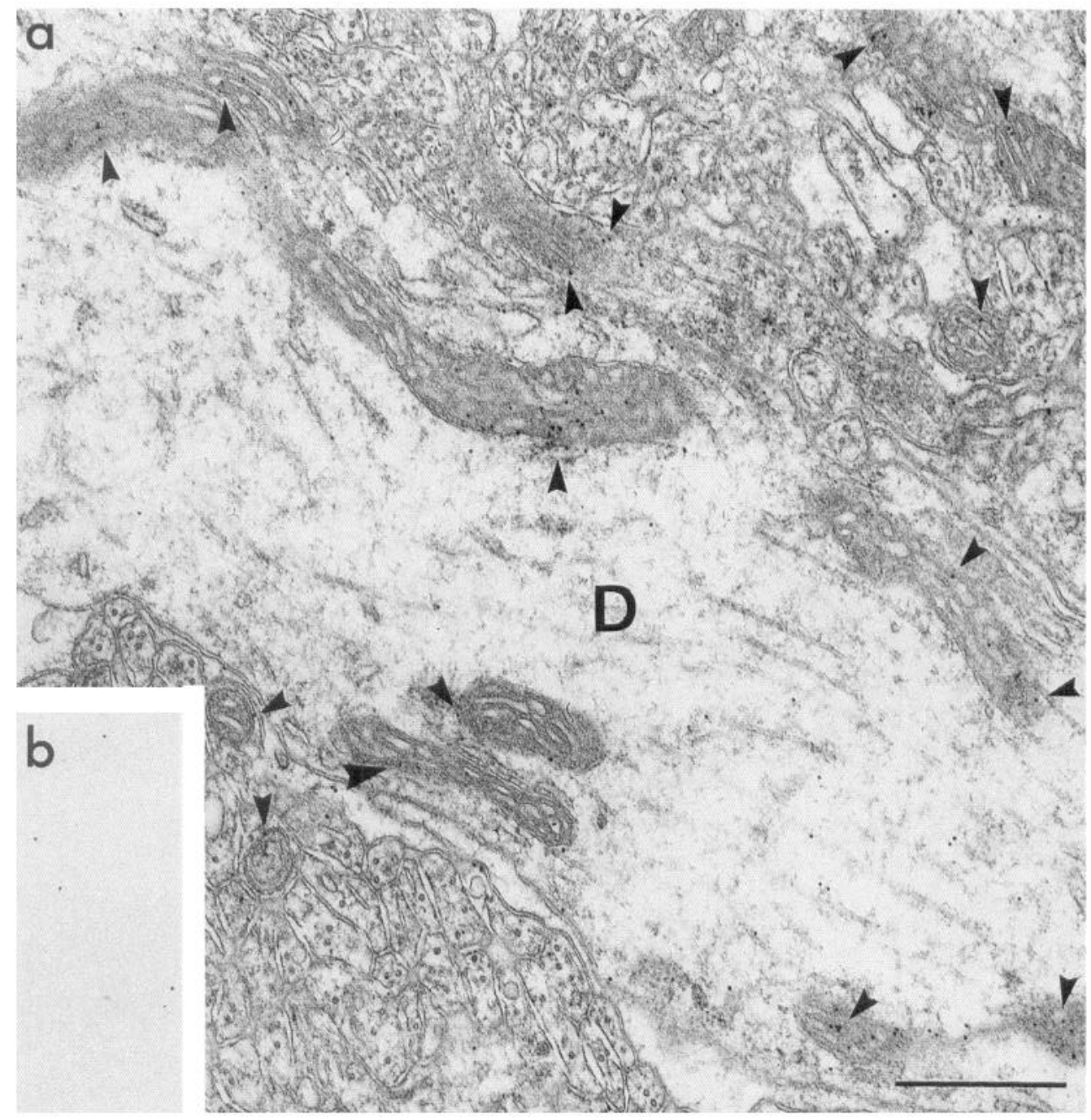

After $15 \mathrm{~d}$ of eye removal, there was a significant reduction in the levels of $\mathrm{CO}$ activity and immunoreactivity of COIV and pCOIV in all three gray layers of the contralateral superior colliculus ( $p<0.05$ to $p<0.001$ ) (Fig. 8, Table 2). Effects were more striking in the superficial gray layer than in the intermediate gray layer, while the deep gray layer was the least affected. At both time points, there were parallel changes in levels of $\mathrm{CO}$ activity and immunoreactivity of COIV and pCOIV.

\section{Discussion}

We present here the first evidence that pCOIV protein is detectable in the mammalian brain in vivo. Moreover, pCOIV is located not only in cell bodies but unexpectedly also in distal dendrites and axon terminals, suggesting that the precursor form of CO subunit IV can be transported to distal processes of neurons and stay there for relatively long periods before it is degraded by mitochondrial matrical proteases. The physical distance between dendritic/axonal mitochondria and the nucleus requires the existence of an efficient transport system to bring newly synthesized mitochondrial proteins from the soma to their distant targets. The proteins could be transported via mitochondrial compartments and/or via dendritic/axonal cytoplasmic flow. Our EM study demonstrates that pCOIV is located mainly in mitochondria and much less so in nonmitochondrial cytoplasm of cell bodies, and almost exclusively in mitochondria of dendrites and axon terminals. This indicates that the bulk of newly synthesized nuclear-encoded precursor proteins are incorporated without delay into mitochondria of neuronal cell bodies and are transported to dendrites and axons within the mitochondrial compartment. If the transportation is mediated by nonmitochondrial cytoplasm of dendrites and axons, one would expect to see immunolabeling mainly in cytoplasm outside of mitochondria. This was not the case. Our results are consistent with previous reports that newly synthesized nuclearderived mitochondrial polypeptides are imported into mitochondria rapidly, probably within $30 \mathrm{sec}$ to $2 \mathrm{~min}$ in the somatic cytoplasm (Mori et al., 1981; Reid et al., 1982). When import was blocked experimentally in cultures of chicken embryo fibroblasts, precursor proteins were found to be degraded within $5 \mathrm{~min}$ in the cytosol (Jaussi et al., 1982). Our data also imply that after the precursor proteins are imported into perikaryal mitochondria, mitochondria are transported away from the somata and are selectively distributed in neuronal processes. Evidence for this is that pCOIV is significantly richer in dendrites and in some axonal terminals (e.g., basket and mossy fiber terminals) than many cell bodies, such as dentate granule cells and cerebellar Purkinje and granule cells.

Our present study also indicates that precursor proteins can 


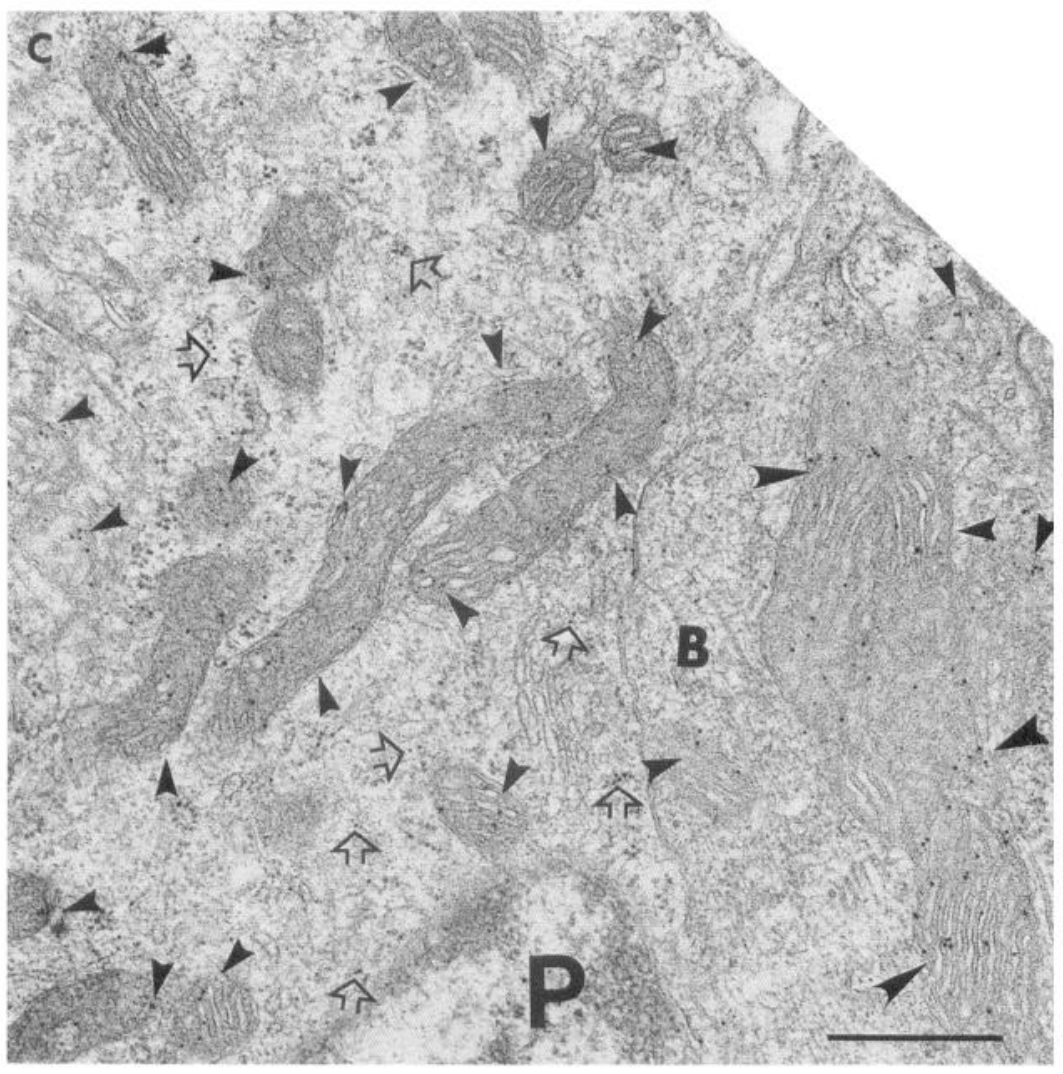

Figure 6. Continued.

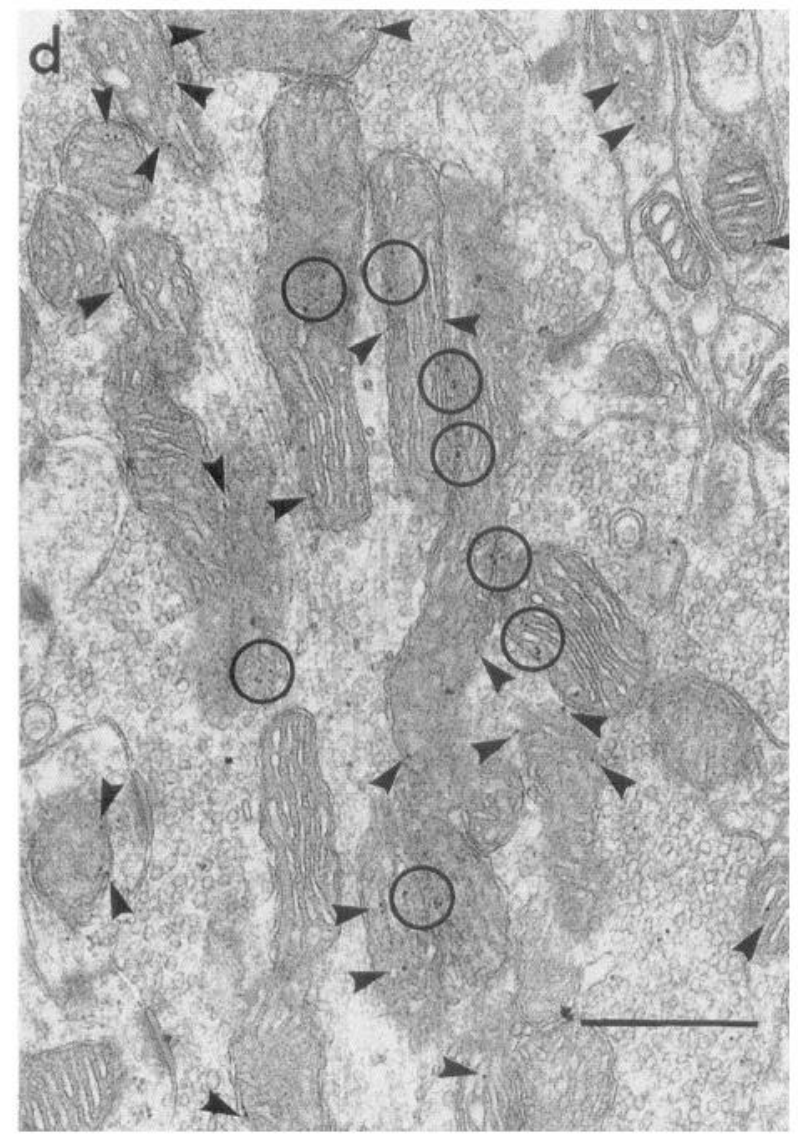

be delivered intramitochondrially over a great distance even to distal dendrites. Mitochondrial movement in neuronal processes involves fast and slow transport along microtubules in a stop-and-go (saltatory) fashion (Jeffrey et al., 1972; Lorenz and Willard, 1978). It seems more efficient for neurons to deliver nuclear-derived mitochondrial proteins to dendritic and axonal destinations via mitochondrial compartments, as our data indicate, rather than via the dendritic cytosol. First, the rate of mitochondrial transport is much faster than that of bulk cytosolic flow (Jeffrey et al., 1972; Lorenz and Willard, 1978; Vale et al., 1985). This would allow proteins to be distributed rapidly to their final destinations. Second, it has been reported that mitochondrial transport in axons in vitro is regulated by both a recruitment between stationary and moving states and direct regulation of anterograde motor (Morris and Hollenbeck, 1993). Different rates of mitochondrial transport provide the opportunity for mitochondria to be shuttled to different neuronal compartments at varying rates regulated by local metabolic demands. Indeed, $\mathrm{CO}$ activity and $\mathrm{CO}$ proteins are both distributed heterogeneously in neurons, and their patterns of distribution correlate with local energy demands (Hevner and WongRiley, 1989; Wong-Riley, 1989). However, we cannot rule out the possibility that (1) a small amount of the precursors may simply diffuse in the extramitochondrial compartment of dendrites and remain undetectable by the present approach, and (2) COIV mRNA might be present in a low amount in distal dendrites, where it is translated to precursor proteins. Our findings of anti-pCOIV in axon terminals, which lack mRNA and ribosomes, further strengthen the posttranslational means of delivery to neuronal processes.

The present study also indicates that in neurons, a pool of 

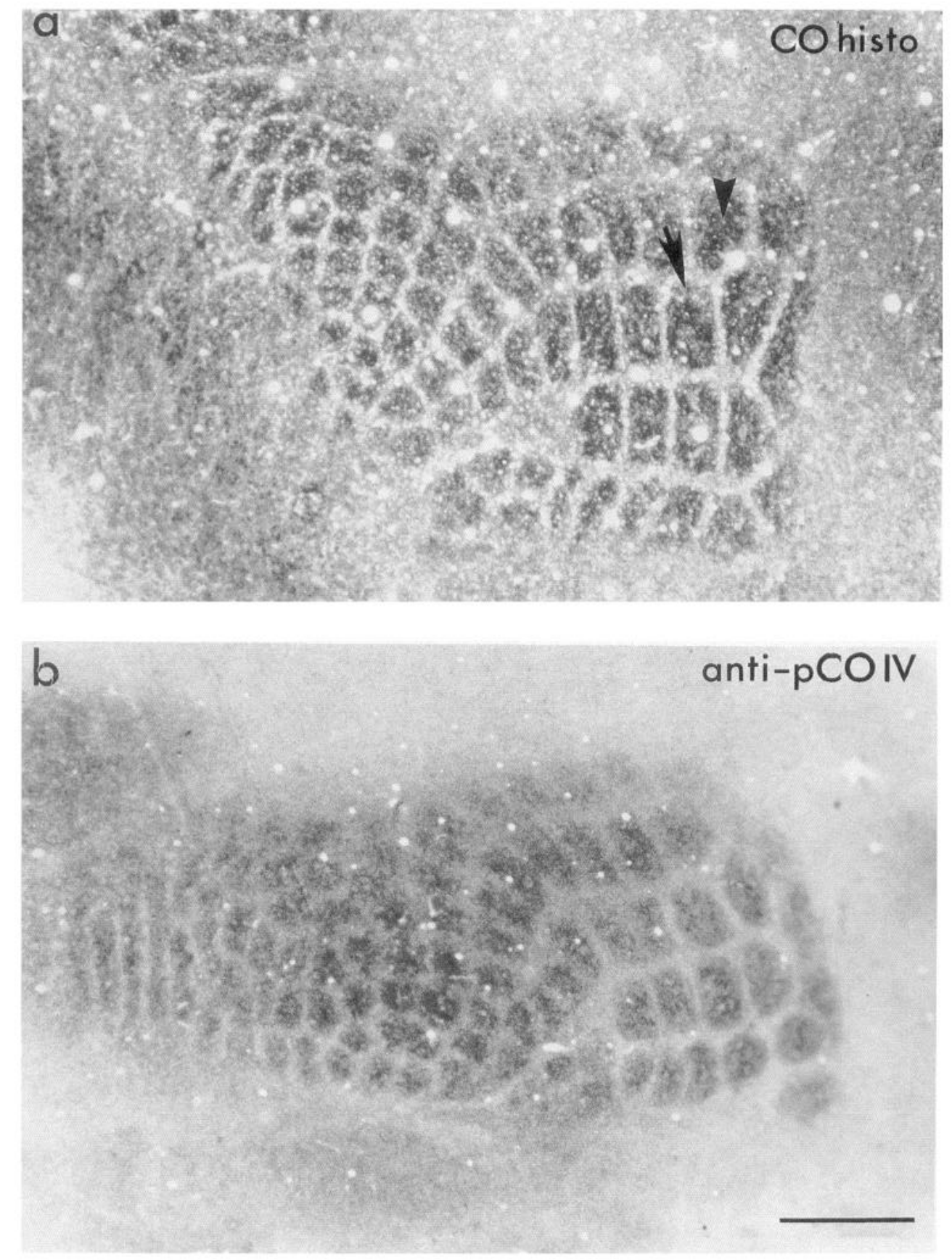

Figure 7. Correlation of $\mathrm{CO}$ activity and pCOIV distribution in rat cortical barrel field. Adjacent tangential sections were reacted for $\mathrm{CO}$ histochemistry (a) and pCOIV immunohistochemistry $(b)$. Each barrel is made up of cell-dense barrel sides (arrow) and cell-sparse barrel hollow (arrowhead). The barrel hollows are darkly reactive for CO activity $(a)$ and for pCOIV immunoreactivity $(b)$, while the barrel sides and septa have low levels of reaction products. A similar distribution pattern was also seen with COIV immunohistochemistry (not shown). Scale bar, 0.3 $\mathrm{mm}$.

pCOIV exists in dendritic and axon terminal mitochondria. Is the accumulation of pCOIV attributable to an overproduction and/or slow maturation of $\mathrm{CO}$ subunit IV in neurons? It has been reported that an excess amount (exceeding mitochondrial requirement) of nuclear-encoded mitochondrial precursor proteins is imported into mitochondria under normal or abnormal conditions (Hundt et al., 1980; Forsburg and Guarente, 1989; Mita et al., 1989). First, nuclear-derived CO subunits could accumulate in mitochondria in the absence of holoenzyme assembly in yeast (Forsburg and Guarente, 1989). Second, free $\mathrm{CO}$ subunit IV in mitochondria could be detected even when mitochondrial-derived subunits are depleted in human muscles with mitochondrial DNA mutation (Mita et al., 1989). Third, $\mathrm{CO}$ is assembled in the absence of cytoplasmic protein synthesis for $5 \mathrm{hr}$ in isolated hepatocytes (Hundt et al., 1980), indicating that biosynthesis of $\mathrm{CO}$ involves large pools of the cytoplasmic precursor. Thus, it is quite likely that pCOIV is overproduced by neurons, and excess pCOIV is imported into mitochondria and contributes to the precursor pool in mitochondria. The exact half-life of pCOIV cannot be determined by the present study; instead, an approximate estimate of minimal half-life for pCOIV is assessed based on the lengths of neuronal dendrites and the rate of mitochondrial transport in mammalian axons. There is evidence for both slow $(1-4 \mathrm{~mm} / \mathrm{d})$ and fast $(50 \mathrm{~mm} / \mathrm{d}) \mathrm{move}-$ ments of mitochondria in normal mammalian axons (Jeffrey et al., 1972; Lorenz and Willard, 1978). The essential features of dendritic transport are quite similar to those in axons (Grafstein and Forman, 1970). By slow movement, pCOIV could have a 


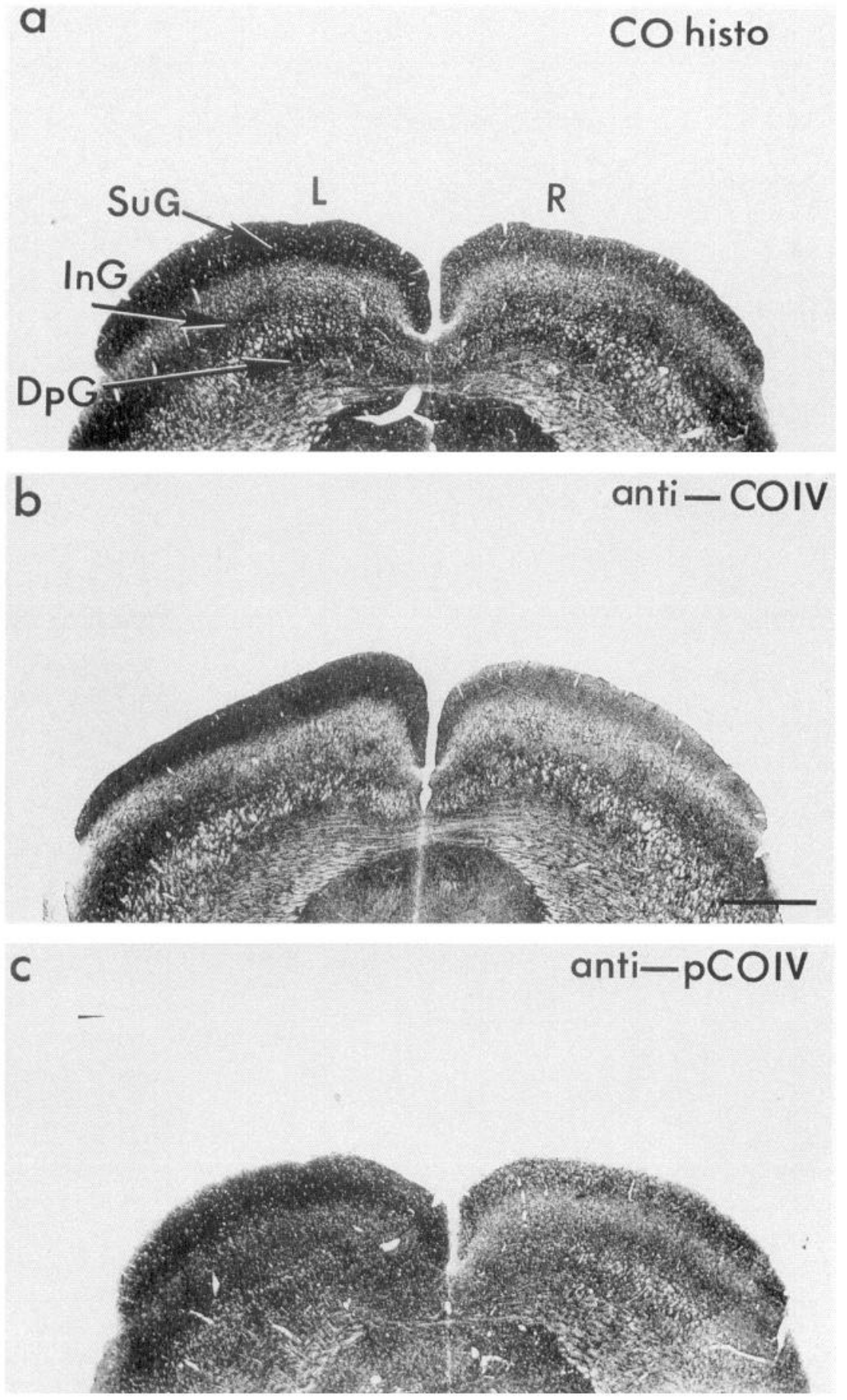

Figure 8. Regulation of pCOIV in the rat superior colliculus by monocular deprivation. Adult rats sustained left enucleation for $15 \mathrm{~d}$. Frozen sections $(20 \mu \mathrm{m})$ of superior colliculus were processed for CO activity $(a)$, COIV $(b)$, and pCOIV $(c)$ immunostaining. Note that $\mathrm{CO}$ activity and levels of COIV and pCOIV are decreased in parallel in the right superior colliculus $(R)$ of all three figures. Superficial gray $(S u G)$, intermediate gray $(\operatorname{In} G)$, and deep gray $(D p G)$ layers were affected to different degrees. Scale bar, $0.5 \mathrm{~mm}$. half-life of at least $2.6 \mathrm{hr}$ (the length of Purkinje cell dendrites is about $220 \mu \mathrm{m}$, and the velocity of mitochondrial transport is averaged to $2 \mathrm{~mm} / \mathrm{d}$ ). In contrast, by fast transport, mitochondria might have a half-life of a few minutes $(220 \mu \mathrm{m}, 50 \mathrm{~mm} /$ d). In sum, it is most likely that the half-life of pCOIV can vary within the same neuron depending on its energy demand, and pCOIV can have a half-life of a few minutes to $2.6 \mathrm{hr}$ or more. This indicates that the processing of pCOIV in the mammalian brain tissue in vivo is considerably slower than precursor proteins found in yeast or in mammalian liver cells (having a halflife of $30 \mathrm{sec}$ to $2 \mathrm{~min}$ ) described by a number of investigators (Mori et al., 1981; Reid et al., 1982). Thus, the slow maturation rate of nuclear-encoded mitochondrial proteins could be one of the mechanisms for preserving a large intramitochondrial precursor pool in neurons.

Besides the accumulation of precursor proteins in mitochondria, other factors need to be ruled out. First, free presequences of precursor proteins may remain in the mitochondria after cleavage. The presequence of the Rieske iron sulfur protein in the bovine heart has been reported to remain in the cytochrome bcl complex as subunit 9 (Brandt et al., 1993). However, we have not been able to detect small molecules in the size range of the presequence ( 22 amino acids) in Western blots or by means of ELISAs. Second, precursors of the rat brain COIV 
Figure 9. A model for possible mechanisms of dendritic transport, selective targeting, maturation, and holoenzyme assembly of nuclear-derived mitochondrial precursor proteins in neuronal dendrites (using cytochrome oxidase as an example). $a$, Nuclear-encoded mitochondrial $\mathrm{CO}$ subunit proteins are synthesized mainly in cell bodies on cytoplasmic polyribosomes as a larger precursor, carrying a cleavable polypeptide (presequence) at the $\mathrm{N}$-terminus, which functions as the targeting signal for directing precursors into mitochondria. The newly synthesized polypeptides are imported into mitochondria rapidly, and some presequences of precursors are cleaved shortly thereafter by specific proteases in the matrix. These nuclear-encoded mature proteins, together with mitochondrialencoded subunits, assemble into $\mathrm{CO}$ holoenzymes in the cell body. However, considerable numbers of precursors are not processed by proteases in cell bodies but are carried within mitochondria to distal dendrites along microtubules. $b$, Highly reactive mitochondria (2), enriched in $\mathrm{CO}$ enzymes and pCOIV, selectively target the dendritic segments where high energy demands are imposed by intense functional activity, while less reactive mitochondria $(l)$ are located in areas with lower energy demands. In response to changes in local energy needs, cytosolic factors (as yet unidentified) could control maturation of nuclear-encoded mitochondrial precursor proteins, and assembly of functional holoenzymes takes place in dendrites (mitochondrion 2 changes to mitochondrion 3). A decrease in the functional demand of postsynaptic dendrites, such as with cessation of afferent input, could also result in a local downregulation of the precursor pool within dendrites. A similar mechanism probably occurs in axon terminals.
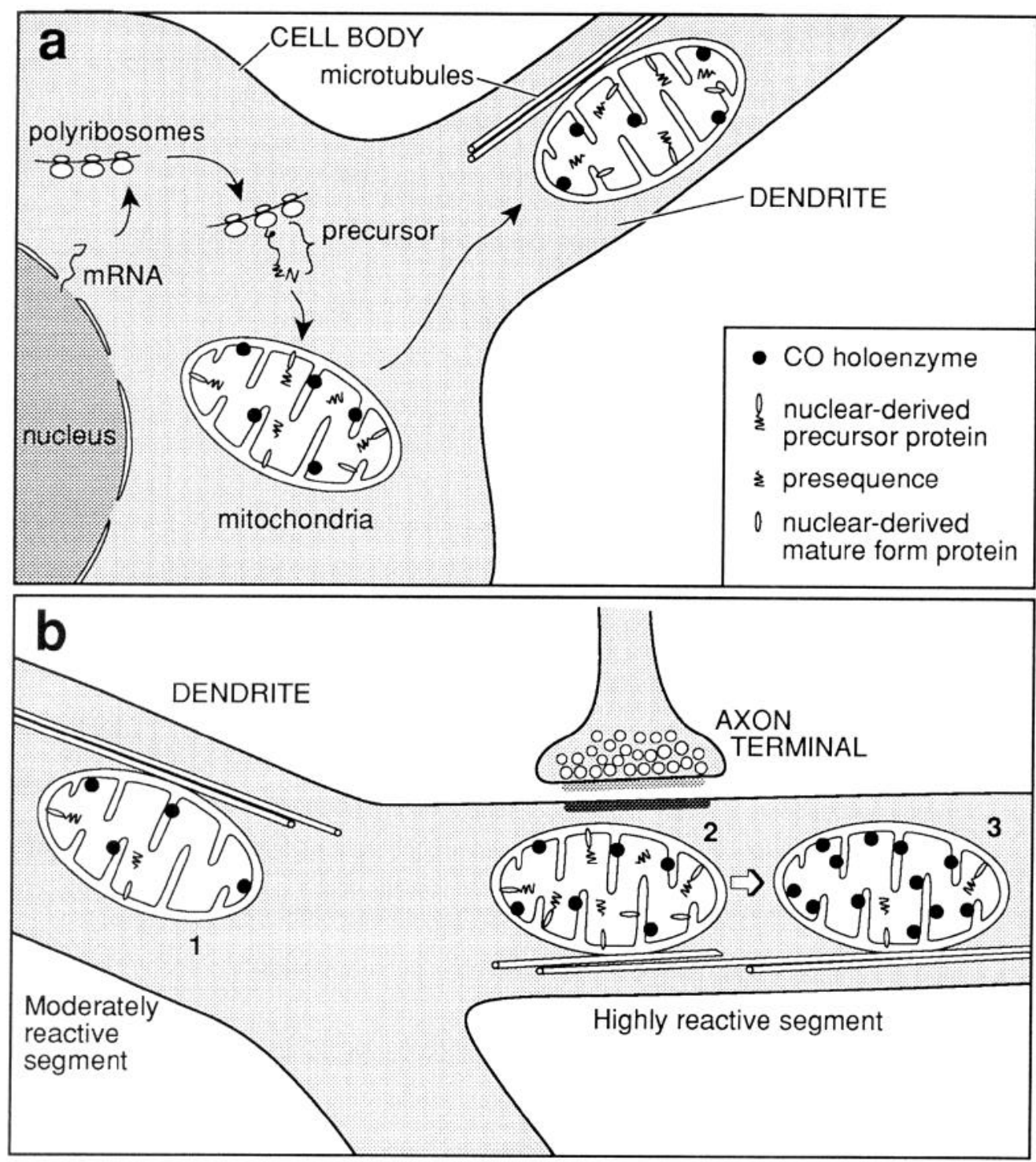

may be processed to its mature form in two steps, as for yeast and human COIV (Hendrick et al., 1989), and the final processing occurs after the intermediate form of COIV is inserted into the enzyme complex. In this case, it would be necessary to postulate that our anti-pCOIV may also recognize an intermediate form of precursor protein.

Our previous study demonstrated that $\mathrm{CO}$ activity is largely controlled by regulation at levels of $\mathrm{CO}$ proteins and $\mathrm{CO}$ subunit mRNAs (Hevner and Wong-Riley, 1990, 1991). The present study shows that levels of pCOIV, the mature form of CO subunit IV, and $\mathrm{CO}$ activity declined proportionately in the rat superior colliculus $15 \mathrm{~d}$ after monocular enucleation. This suggests that the mitochondrial $\mathrm{CO}$ precursor pool can be regulated by neuronal functional activity, and changes in $\mathrm{CO}$ proteins depend more on altering protein synthesis than on protein degradation. However, our data cannot exclude the possibility that the decrease in the amount of pCOIV is due to the rapid processing of the precursor protein to the mature form after enucleation.
Since distributions of $\mathrm{CO}$ activity and $\mathrm{CO}$ proteins are controlled by local energy demands (Hevner and Wong-Riley, 1989, 1990; Wong-Riley, 1989), it appears likely that the level of pCOIV in brain is also regulated by metabolic demands imposed by functional activity. A model pertaining to dendrites (but equally applicable to axon terminals) is presented in Figure 9, and it raises the possibilities that (1) the proteolytic processing of precursors and assembly of $\mathrm{CO}$ holoenzymes might take place in neuronal dendrites, and (2) dendritic cytosol may have an active role in controlling the maturation of these precursors. This has very important implications because metabolic demands differ in various segments of dendrites, and neurons may have an as yet unknown mechanism to supply mitochondria to appropriate microdomains in order to meet local metabolic demands. A previous study suggests that ADP could be the molecule that signals mitochondria to cease movement (BereiterHahn and Voth, 1983), which could result in the clustering of mitochondria in regions of high ATP demand. CO is one of the key enzymes for ATP production to fuel energy-consuming neu- 
ronal functions. Thus, when and where these precursors could be converted to their mature forms and be further assembled into $\mathrm{CO}$ holoenzymes are factors relevant to neuronal functioning. The intramitochondrial precursor pool is a potential source capable of being converted to mature proteins for assembly in dendrites. Mitochondria contain their own genetic apparatus, and the local content of mtDNA is similar to $\mathrm{CO}$ activity and $\mathrm{CO}$ amount (Hevner and Wong-Riley, 1991). Furthermore, significant amounts of mitochondrial-encoded mRNAs of CO subunit I were found in neuronal dendrites (Hevner and Wong-Riley, 1991). Thus, mechanisms are present for a ready source of mitochondrial- and nuclear-derived subunit polypeptides within dendritic mitochondria for $\mathrm{CO}$ holoenzyme assembly. Although it has been reported that, in neurons, mitochondria can periodically shuttle back to cell bodies for supply and renewal (Grafstein and Forman, 1970), this is a time-consuming process in response to alterations in dendritic and terminal energy demands. In contrast, it would be much more efficient for neurons to control maturation of subunit proteins and assembly of mitochondrial holoenzymes in local dendrites/ axons by as yet unidentified dendritic/axonal cytosolic factors. This may allow neurons to regulate mitochondrial enzyme activities locally, precisely, and rapidly in response to changes in their functional activities.

In conclusion, the present study indicates that pCOIV in mitochondria can accumulate as a precursor pool, travel to neuronal dendrites and axon terminals via the mitochondrial compartment, and are selectively distributed in different brain regions, with a pattern similar to those of mature COIV and of $\mathrm{CO}$ activity. The half-life of precursor protein in neurons is likely to be considerably longer than previously reported in other cell types, and its level is regulated by neuronal activity.

\section{References}

Bereiter-Hahn J, Voth M (1983) Metabolic control of shape and structure of mitochondria in situ. Biol Cell 47:309-322.

Brandt U, Yu L, Yu CA, Trumpower BL (1993) The mitochondrial targeting presequence of the Rieske iron sulfur protein is processed in a single step after insertion into the cytochrome $b_{c_{1}}$ complex in mammals and retained as a subunit in the complex. J Biol Chem 268: 8387-8390.

Forsburg SL, Guarente L (1989) Communication between mitochondria and the nucleus in regulation of cytochrome genes in yeast Saccharomyces cerevisiae. Annu Rev Cell Biol 5:153-180.

Fujimoto N, Goeke M, Olson BJ, Klenk DC (1985) Measurement of small masses of protein with bicinchoninic acid. Anal Biochem 157: 291-294.

Goto Y, Naoki A, Taro O (1989) Nucleotide sequence of cDNA for rat brain and liver cytochrome $\mathrm{c}$ oxidase subunit IV. Nucleic Acids Res 17:2851.

Grafstein B, Forman DS (1980) Intracellular transport in neurons. Physiol Rev 60:1167-1283.

Harlow E, Lane D (1988) Antibodies. A laboratory manual, p 673. Cold Spring Harbor, NY: Cold Spring Harbor Laboratory.

Hartl FU, Pfanner N, Nicholson DW, Neupert W (1989) Mitochondrial protein import. Biochim Biophys Acta 988:1-45.

Hendrick JP, Hodges PE, Rosenburg LE (1989) Survey of aminoterminal proteolytic cleavage sites in mitochondrial precursor proteins: leader peptides cleaved by two matrix proteases share a threeamino acid motif. Proc Natl Acad Sci USA 86:4056-4060.
Hevner RF, Wong-Riley MTT (1989) Brain cytochrome oxidase: purification, antibody production, and immunohistochemical/histochemical correlations in the CNS. J Neurosci 9:3884-3898.

Hevner RF, Wong-Riley MTT (1990) Regulation of cytochrome oxidase protein levels by functional activity in the macaque monkey visual system. J Neurosci 10:1331-1340.

Hevner RF, Wong-Riley MTT (1991) Neuronal expression of nuclear and mitochondrial genes for cytochrome oxidase $(\mathrm{CO})$ subunits analyzed by in situ hybridization: comparison with $\mathrm{CO}$ activity and protein. J Neurosci 11:1942-1958.

Hundt E, Trapp M, Kadenbach B (1980) Biosynthesis of cytochrome $c$ oxidase in isolated rat hepatocytes. FEBS Lett 115:95-99.

Jaussi R, Sonderegger P, Fluckiger J, Christen P (1982) Biosynthesis and topogenesis of aspartate aminotransferase isoenzymes in chicken embryo fibroblasts. The precursor of the mitochondrial isoenzyme is either imported into mitochondria or degraded in the cytosol. J Biol Chem 257:13334-13340.

Jeffrey PL, James KAC, Kidman AD, Richards AM, Austin L (1972) The flow of mitochondria in chicken sciatic nerve. J Neurobiol 3:199208.

Kadenbach B, Jarausch J, Hartmann R, Merle P (1983) Separation of mammalian cytochrome $c$ oxidase into 13 polypeptides by a sodium dodecyl sulfate-gel electrophoretic procedure. Anal Biochem 129:517-521.

Kaput J, Goltz S, Blobel G (1982). Nucleotide sequence of the yeast nuclear gene for cytochrome $c$ peroxidase precursor. J Biol Chem 257: $15054-15058$.

Lorenz T, Willard M (1978) Subcellular fractionation of intra-axonally transported polypeptides in the rabbit visual system. Proc Natl Acad Sci USA 75:505-509.

Maccecchini ML, Rudin Y, Blobel G, Schatz G (1979) Import of proteins into mitochondria: precursor forms of the extramitochondrially made $F_{1}-A T P a s e$ subunits in yeast. Proc Natl Acad Sci USA 76:343-347.

Mita S, Schmidt B, Schon EA, DiMauro S, Bonilla E (1989) Detection of "deleted" mitochondrial genomes in cytochrome- $c$ oxidase-deficient muscle fibers of a patient with Kearns-Sayre syndrome. Proc Natl Acad Sci USA 86:9509-9513.

Mjaatvedt AE, Wong-Riley MTT (1988) Relationship between synaptogenesis and cytochrome oxidase activity in Purkinje cells of the dcvcloping rat ccrcbcllum. J Comp Neurol 277:155-182.

Mori M, Morita T, Ikeda F, Amaya Y, Tatibana M, Cohen PP (1981) Synthesis, intracellular transport, and processing of the precursors for mitochondrial ornithine transcarbamylase and carbamoylphosphate synthetase $I$ in isolated hepatocytes. Proc Natl Acad Sci USA 78: 6056-6060.

Morris RL, Hollenbeck PJ (1993) The regulation of bidirectional mitochondrial transport is coordinated with axonal outgrowth. J Cell Sci 104:917-927.

Reid GA, Yonetani T, Schatz G (1982) Import of proteins into mitochondria: import and maturation of the mitochondrial intermembrane space enzymes cytochrome $b_{2}$ and cytochrome $c$ peroxidase in intact yeast cells. J Biol Chem 257:13068-13074.

Vale RD, Schnapp BJ, Reese TS, Sheetz MP (1985) Movement of organelles along filaments dissociated from the axoplasm of the squid giant axon. Cell 40:449-454.

Viebrock A, Perz A, Sebald W (1982) The imported preprotein of the proteolipid subunit of the mitochondrial ATP synthase from Neurospora crassa. Molecular cloning and sequencing of the mRNA. EMBO J 1:565-571.

Wong-Riley MTT (1979) Changes in the visual system of monocularly sutured or enucleated cats demonstrable with cytochrome oxidase histochemistry. Brain Res 171:11-28.

Wong-Riley MTT (1989) Cytochrome oxidase: an endogenous metabolic marker for neuronal activity. Trends Neurosci 12:94-101. 